\author{
M. Padberg \\ S.F.T.M. de Bruijn \\ D.L.J. Tavy
}

\section{Neck pain in chronic whiplash syndrome treated with botulinum toxin. A double-blind, placebo-controlled clinical trial}

Received: 2 February 2006

Received in revised form: 7 June 2006

Accepted: 13 June 2006

Published online: 7 March 2007

M. Padberg, MD (ه)

Dept. of Neurology

Haga Hospital

Leyweg 275

$2545 \mathrm{CH}$, The Hague

The Netherlands

Tel.: +31-70-3592997

E-Mail: m.padberg@hagaziekenhuis.nl

S.F.T.M. de Bruijn, MD, PhD

Dept. of Neurology

Haga Hospital

The Hague, The Netherlands

D.L.J. Tavy, MD

Dept. of Clinical Neurophysiology

Haga Hospital

The Hague, The Netherlands
Abstract Objectives Neck pain in chronic whiplash syndrome is a major burden for patients, healthcare providers and insurance companies. Randomized data on treatment of botulinum toxin in chronic whiplash syndrome are scarce. We conducted a randomized, placebo-controlled clinical trial to prove efficacy of botulinum toxin for neck pain in chronic whiplash syndrome. Methods 40 patients with chronic whiplash syndrome (whiplash associated disorders grade 1 and 2) were randomly assigned to receive botulinum toxin (maximum 100 units) or placebo (saline) in muscles with increased tenderness. Results After 12 weeks there was no significant difference between the two treatment groups in decrease of neck pain intensity on VAS $(-7.0 \mathrm{~mm}, 95 \%$ confidence interval (CI) $[-20.7$ to +6.7$])$, mean number of neck pain days $(-1 \% ; 95 \%$ CI $[-15 \%$ to $+13 \%])$, neck pain hours per day $(-0.14$; $95 \%$ CI [ -3.0 to +2.7$])$, days on which symptomatic treatment was taken $(-0.7 \%$; $95 \%$ CI $[-15 \%$ to $+13 \%]$ ) number of analgesics taken per day $(-0.14 ; 95 \%$ CI $[-0.6$ to +0.4$])$ and total cervical range of motion (-11 degrees; 95\% CI -40 to +17$])$. There also was no significant difference in patient's assessment of improvement after week 4, 8 and 12. Conclusions Botulinum toxin was not proven effective in treatment of neck pain in chronic whiplash syndrome. Increased muscle tenderness alone might not be the major cause of neck pain in whiplash syndrome.

Key words neck pain. chronic whiplash syndrome . botulinum toxin

\section{Introduction}

Intractable chronic neck pain after a whiplash trauma is a major burden for patients, healthcare providers and insurance companies. It is estimated that $14-42 \%$ of patients develop chronic symptoms after an acute whiplash trauma [2].

These patients often have reduced mobility of the neck with tender muscles and increased muscle activity [25]. Pathophysiology is still unknown, but myofascial triggerpoints can develop in cervical muscles from excessive neck and shoulder muscle contraction due to an overt injury such as acceleration of the neck in a motor vehicle accident [5]. Botulinum toxin is used to treat a variety of neurological disorders associated with pathologically increased muscle tone.

Two previous studies have reported that botulinum toxin might be successful in patients with chronic neck pain following whiplash injuries $[6,12]$. These studies were uncontrolled and the follow-up period was relatively short. In a randomized placebo- 
controlled trial involving 26 patients with chronic neck complaints after whiplash injury a significant improvement on total pain was suggested $[7,8]$.This study however has some methodological problems, such as a relatively short follow-up period of 4 weeks and a small sample size $[7,8]$. Based upon the present evidence botulinum toxin cannot be recommended as standard treatment for chronic neck pain after whiplash injury.

We therefore conducted a double blind placebocontrolled randomized trial to confirm if botulinum toxin in treatment of neck pain is indeed effective in chronic whiplash syndrome.

\section{Methods}

\section{Patients}

Patients were eligible if they had a whiplash type neck distortion defined as a soft tissue injury of the neck following a vehicle collision, with symptoms lasting longer than 6 months. They also met criteria of the Quebec Task Force grade 1 or 2 whiplash-associated disorders (WAD). WAD grade 1 means only neck pain and stiffness and grade 2 requires also musculoskeletal signs, e.g. a decreased range of motion [24]. Exclusion criteria were: age < 18; pregnancy; neuromuscular disorders; previous use of other investigational new drugs in the past 30 days prior to the screening visit; previous use of botulinum toxin; traumatic abnormalities on radiological examinations. The institutional ethics committee approved the study protocol, and patients gave informed consent before inclusion.

\section{Study design}

The trial had a double-blind, placebo-controlled parallel design. After patient's consent was obtained, we recorded demographics (age, gender). During a baseline-period of 4 weeks, patients used a diary to record the presence of neck pain, number of neck pain hours per day, number of days on which medication was taken, and number of tablets taken per day. At the end of this baselineperiod (week 0) patients recorded their mean neck pain intensity scored on $100 \mathrm{~mm}$ Visual Analogue Scale of the previous 4 weeks (week -4 to 0 , VAS-pre-treatment). At week 0 , patients were randomly assigned to receive 100 units botulinum toxin (Botox ${ }^{\circledR}$ ) or placebo (saline) in $2 \mathrm{cc}$ syringes. At 12 weeks follow-up they recorded again their mean neck pain intensity of the previous 12 weeks (week 0 to 12 , VAS-post-treatment). The local trial pharmacist prepared the drug, coded the syringes, and kept treatment codes. The pharmacist had no further participation in the trial. An experienced clinical neurophysiologist (D.T.) performed all injections. Injection sites were selected individually (i.e. 'follow the pain' approach) in muscles with clinically increased muscle tone or muscle tenderness, and included $\mathrm{m}$. occipitofrontalis, m.temporalis, m. masseter, m. sternocleidomastoideus, $\mathrm{m}$. splenius capitis, $\mathrm{m}$. trapezius and $\mathrm{m}$. semispinalis.

\section{Outcomes}

After patients were injected at week 0 in one single treatmentsession, clinical characteristics were recorded using diaries during the 12 weeks post-treatment. The primary outcome measure was the intensity of the neck pain of the total study period, week $0-12$, scored on the VAS at week 12 (one single measurement) compared with baseline (VAS week -4 to 0 ). Patients were asked to rate (in a single value) severity of neck pain which at times may be mild and perhaps at others severe, by "integrating severity over time".

Secondary outcome measures were average number of neck pain days, average number of neck pain hours per day, average number of days on which symptomatic treatment was taken, mean number of symptomatic tablets per day at 12 weeks compared with baseline. Additionally, a blinded investigator asked patients whether there was any improvement in their condition after 4, 8 and 12 weeks in the two treatment groups (five-point scale: great worsening, any worsening, no improvement, any improvement and great improvement). Range of cervical motion was measured with a cervical range of motion (CROM) device to measure the six conventional movements of the spine at week 12 compared with baseline. For measurements of CROM, the patients were seated in a chair with their shoulders supported on a backrest. Patients were instructed to assume a comfortable position and then to perform each required movement and return to the start position. The movements were assessed in this order: right rotation, left rotation, right flexion, left flexion, extension, flexion and then summated to determine the mean total range of motion.

We also divided all patients in responders and non-responders at week 12 . We considered at least $45 \%$ reduction in the VAS compared with baseline to be clinically relevant (e.g. responder). All adverse events during the 3 months follow-up were recorded by the investigators.

\section{Sample size determination}

At baseline we expected mean neck pain intensity on the VAS of 40/ $100 \mathrm{~mm}$. The estimated placebo effect was a $8 \mathrm{~mm}$ reduction to a VAS intensity of $32 / 100$ at 12 weeks. We hypothesized a $18 \mathrm{~mm}$ reduction in the treatment group to a VAS intensity of $22 / 100$, although there are no earlier data on treatment effect of BTX in these patients. To detect this clinically relevant effect ( 8 versus $18 \mathrm{~mm}$ improvement) at a $5 \%$ level of statistical significance (twotailed), with a power of $80 \%$, a total of 40 patients was needed.

\section{Statistical analysis}

We calculated mean differences between baseline VAS data and VAS data after 12 weeks, using the t-test; statistical uncertainty was expressed in $95 \%$ confidence intervals. The responders at week 12 in each treatment group and the differences in improvement scores were compared by use of the Chi-square test. All these analysis were done with SPSS (version 10.0).

\section{Results}

Between November 1999 and March 200340 patients were included at Leyenburg hospital The Hague. Of the 59 patients assessed for eligibility, 19 patients were excluded. Four patients did not meet the inclusion criteria, eight patients refused to participate and seven patients withdrew in the baseline period. No patient was lost to follow-up.

In 1 patient the neck pain diary was incomplete during the whole study period (missing data on neck pain duration, days on which medication was taken and mean number of tablets per day). In 7 patients the neck pain diary for the post-treatment period was 
partly incomplete (missing data on neck pain duration, days on which medication was taken and mean number of tablets per day). There were no differences in baseline characteristics between the two treatment groups. Neck pain intensity, VAS at baseline was $64.5 \mathrm{~mm}(\mathrm{SD}=14.8)$ in the botulinum group and $62.1(\mathrm{SD}=20.3)$ in the placebo group (Table 1).

At 12 weeks the VAS scores were $52.0 \mathrm{~mm}$ $(\mathrm{SD}=29.2)$ in the botulinum group and $56.7 \mathrm{~mm}$ $(S D=29.6)$ in the placebo group. Mean differences between VAS pre- and post-treatment was 12.5 in the botulinum group and 5.5 in the placebo group. The therapeutic gain ( = difference in improvement between the two treatment groups measured in $\mathrm{mm}$ ) was $-7.0(\mathrm{p}=0.31 ; 95 \%$ CI $(-20.7$ to +6.7$))$. Six patients in the botulinum group were responders as defined, versus four in the placebo group (NS, $\mathrm{p}=0.5$ ).

Patients' assessment of improvement/worsening showed no significant difference between the two groups at week $4(\mathrm{p}=0.9)$, week $8(\mathrm{p}=0.4)$ and 12 $(\mathrm{p}=0.4)($ Table 2$)$.

There were no significant differences between the two treatment groups in mean number of neck pain days, mean number of neck pain hours per day, mean number of days on which medication was taken, and mean number of tablets taken per day pre- and posttreatment (Table 3).

At baseline all patients showed a reduced cervical range of motion (CROM) in all directions [9]. There was a slight improvement in total CROM in favour of the botulinum group. However, CROM was not significantly different between BTX group and placebo, nor between responders and non-responders.

Twenty-seven patients reported minor side-effects, 15 in the botulinum toxin group and 12 in the placebo group. The main complaint was "short-lasting pain at the injection sites".

\section{Discussion}

Our study could not demonstrate botulinum toxin to be more effective than placebo in treatment of neck pain in patients with chronic whiplash syndrome.

Previous open label studies with botulinum toxin in patients with chronic whiplash syndrome suggested some beneficial effect on neck pain [12]. Our study is the second published randomized-controlled trial to determine efficacy of botulinum toxin in patients with chronic whiplash syndrome. The other randomized placebo-controlled trial in 26 patients with chronic whiplash syndrome reported a beneficial effect of botulinum toxin $[7,8]$.

This study, however, has some methodological shortcomings. Primary outcome was improvement of headache intensity scored on the VAS after 4 weeks compared with baseline. The post treatment difference between the two treatment groups was reported to be significant. However, baseline-characteristics were significantly different, with a significant higher headache intensity in the botulinum group at baseline. (VAS 6.5 (range 2-9) versus $3.0(0-8)$ in the placebo group $(\mathrm{p}<0.01))$. The reported improvement may mainly have been caused by the unequal distribution of the patients at baseline. In their second publication ( on the same trial) the mean total pain score was reported, ranging from $0-30$, expressing the total pain experience for neck pain, headache and shoulder pain. After 4 weeks the mean total pain was 10.0 (SE 1.3) in the botulinum group and 14.1(SE 21) in the placebo group, which was also reported to be significant. These data are difficult to interpret without individual scores. Calculation of the standard deviation could suggest that some patients even had a negative mean total pain score. In any case, the distribution was truncated and skew to the right.

There are some points of discussion in our study. We used injections at trigger points on an individual basis, instead of following a standardized protocol. This might seem subjective and arbitrary, but resembles clinical practice and is usually recommended for botulinum toxin (BTX) treatment in pain syndromes $[10,16]$. We used doses of $100 \mathrm{U}$ Botox ${ }^{\circledR}$, which should be sufficient for a single treatment session. There was only slight, not significant, improvement of cervical range of motion in the botulinum group, suggesting some, if any, effect on muscle tenderness. Also, none of our patients reported muscular weakness as a side effect. Therefore, further increase of the dosage of botulinum toxin might be possible. There is some evidence that multiple treatment sessions are needed for sufficient clinical benefit [20]. In our study there was not even a trend for a positive treatment effect after this single treatment session of BTX. Still, a positive effect of multiple treatment injections cannot be entirely ruled out [16].

Pathophysiology of chronic pain in whiplash syndrome is still a matter of debate. There is evidence that myofascial pain is a major factor in chronic pain syndromes like chronic neck pain and chronic tension-type headache [14]. The hypothesis of BTX being effective in chronic whiplash syndrome could be pain reduction by decreasing muscle tenderness and/or activity. If increased muscle tenderness is a key feature in chronic neck pain after a whiplash injury, a more beneficial effect of BTX would have been expected. However, in other chronic pain syndromes where muscle tenderness is thought to play a role BTX was also proven ineffective $[17,23]$. BTX might only be effective in neck pain in combination with cervical dystonia [26]. In our study were no patients with cervical dystonia. 
Table 1 Baseline characteristics

\begin{tabular}{lcc}
\hline Characteristic & Botulinum toxin $(\mathrm{n}=20)$ & Placebo $(\mathrm{n}=20)$ \\
\hline Mean age, years (range) & $39(20-58)$ & $34(20-49)$ \\
Female sex (\%) & $14(70 \%)$ & $13(65 \%)$ \\
Ongoing claims & $15(75 \%)$ & $18(90 \%)$ \\
Mean duration of pain, months (SD) & $40(71)$ & $37(20)$ \\
Neck pain severity, mean VAS (SD) & $64.5(14.8)$ & $62.1(20.3)$ \\
Mean number of neck pain days, \% (SD) & $97 \%(11)^{* 1}$ & $96 \%(12)$ \\
Mean neck pain duration per day, hours (SD) & $12.7(4.0) * 3$ & $11.7(4.5)$ \\
Mean number of medication days, \% (SD) & $50 \%(41) * 1$ & $36 \%(40)$ \\
Mean number of analgesics per day, tablets (SD) & $1.4(1.9)$ & $1.3(2.1)$ \\
Mean total cervical range of motion, degrees (SD) & $266(73)^{* 1}$ & $266(60) * 1$ \\
\hline
\end{tabular}

${ }^{* 1}=$ one missing data; ${ }^{* 3}=$ three missing data

Table 2 Improvement scale

\begin{tabular}{|c|c|c|c|c|c|c|}
\hline \multirow[b]{2}{*}{ Improvement } & \multicolumn{2}{|l|}{ At 4 weeks } & \multicolumn{2}{|l|}{ At 8 weeks } & \multicolumn{2}{|l|}{ At 12 weeks } \\
\hline & Botulinum toxin $(n=20)$ & Placebo $(n=20)$ & Botulinum toxin $(n=20)$ & Placebo $(n=20)$ & Botulinum toxin $(n=20)$ & Placebo $(n=20)$ \\
\hline Great worsening & 4 & 0 & 0 & 2 & 1 & 2 \\
\hline Any worsening & 2 & 4 & 1 & 4 & 2 & 3 \\
\hline No improvement & 6 & 8 & 8 & 7 & 6 & 8 \\
\hline Any improvement & 5 & 5 & 5 & 4 & 5 & 4 \\
\hline Great improvement & 2 & 3 & 6 & 3 & 6 & 3 \\
\hline Total & $19^{* 1}$ & 20 & 20 & 20 & 20 & 20 \\
\hline
\end{tabular}

${ }^{* 1}=$ one missing data

Table 3 Secondary outcome measures

\begin{tabular}{|c|c|c|c|}
\hline Outcome & Botulinum toxin $(n=20)$ & Placebo $(n=20)$ & Therapeutic gain $(95 \% \mathrm{Cl})$ \\
\hline \multicolumn{4}{|l|}{ Neck pain days $(\% \pm S D)$} \\
\hline Baseline (4 weeks) & $97 \%(11) * 1$ & $96 \%(12)$ & \\
\hline Post-treatment (12 weeks) & $89 \%(23) * 2$ & $89 \%(25) * 2$ & \\
\hline Mean difference & $8 \%(18)$ & $7 \%(22)$ & $-1 \%(-15 \%$ to $+13 \%)$ \\
\hline \multicolumn{4}{|c|}{ Neck pain duration (hours/day \pm SD) } \\
\hline Baseline (4 weeks) & $12.7(4.0) * 3$ & $11.7(4.5)$ & \\
\hline Post-treatment (12 weeks) & $12.2(4.6) * 7$ & $11.0(5.1) * 2$ & \\
\hline Mean difference & $0.86(2.2)$ & $0.72(4.7)$ & $-0.14(-3.0$ to +2.7$)$ \\
\hline \multicolumn{4}{|c|}{ Days on which analgesics were taken $(\% \pm S D)$} \\
\hline Baseline (4 weeks) & $49 \%(42 \%)$ & $35 \%(40 \%)$ & \\
\hline Post-treatment (12 weeks) & $42 \%(38 \%) * 3$ & $24 \%(32 \%) * 2$ & \\
\hline Mean difference & $6.4 \%(16 \%)$ & $5.7 \%(24 \%)$ & $0.7 \%(-15 \%$ to $+13 \%)$ \\
\hline \multicolumn{4}{|c|}{ Number of analgesics taken per day (tablets/day \pm SD) } \\
\hline Baseline (4 weeks) & $1.4(1.9) * 1$ & $1.3(2.1)$ & \\
\hline Post-treatment (12 weeks) & $1.2(1.8) * 2$ & $0.95(1.9) * 1$ & \\
\hline Mean difference & $0.32(0.8)$ & $0.18(0.6)$ & $-0.14(-0.6$ to +0.4$)$ \\
\hline \multicolumn{4}{|c|}{ Total cervical range of motion (degrees \pm SD) } \\
\hline Baseline & $266(73) * 1$ & $266(60) * 1$ & \\
\hline Post-treatment (week 12) & $293(59) * 2$ & $277(62) * 3$ & \\
\hline Mean difference & $22(43)$ & $11(36)$ & $-11(-40$ to +17$)$ \\
\hline
\end{tabular}

$*^{1}=$ one missing data; ${ }^{2}=$ two missing data; ${ }^{* 3}=$ three missing data $*^{7}=$ seven missing data

Patients with chronic whiplash syndrome also form a very heterogeneous group, with a wide spectrum of symptoms, varying from neck pain to headache, with pain of different degrees. Many different factors seem to play a role in the development of acute and chronic pain after a whiplash injury.
There is ample evidence that central mechanisms might play a more important role in the development of chronic neck pain in whiplash patients [4], as in other chronic pain syndromes. Damaged peripheral tissue releases inflammatory mediators (like bradykinine and prostaglandins) that changes 
the sensitivity of high-threshold nociceptors (peripheral sensitization). This, in turn, sets up changes in the responsiveness of neurons in the central nervous system (CNS), ultimately increasing the excitability of neurons within the CNS, representing central sensitization [21]. Patients with chronic whiplash syndrome display exaggerated pain after sensory stimulation as a consequence of this state of hyperexcitability of the central nociceptive system $[1,13]$. In other words, an alteration in function of the central nervous system, the way it responds to normal inputs, seems present in these patients.

This central hypersensivity is probably independent of the nociceptive input arising from the painful and tender muscles [4], and possibly a consequence of deficient pain inhibitory systems.

Many somatic, psychological or cultural factors may influence central sensitization. Different studies show that prognosis of chronic whiplash syndrome is also dependent on cultural factors $[15,18,22]$. It has even been shown that presence or absence of compensation claims is one of the most important predictors of bad outcome in patients after whiplash injury (also present in our group in $75-90 \%$ of the patients) $[11,19]$. The etiological contribution of all different psychological factors, like for example coping style [3], to central sensitization is not yet clarified. It is not to be predicted that BTX will improve all different factors, especially psychological and cultural factors, which may contribute to development of this chronic whiplash syndrome.

Based on present evidence BTX cannot be recommended as treatment for neck pain in chronic whiplash patients. Future studies directed on possible central mechanisms of this complicated chronic pain syndrome are warranted.

\section{Contributors}

The trial was designed by S.F.T.M. de Bruijn, D.L.J. Tavy and M. Padberg. Statistical analysis was performed by M. Padberg.

\section{Conflict of interest statement}

Non declared.

Acknowledgement Appreciation is expressed to N. van der Lubbe and A. Heering (department physical therapy), R.J. de Haan and R. Wolterbeek for their statistical advices. To D. Janssen for her assistance in data collection. Allergan provided the study medication, but was not involved in the collection, analysis and interpretation of the data. This trial was supported by a financial grant from the Dr. Eduard Hoelen Foundation at The Hague.

\section{References}

1. Banic B, Petersen-Felix S, Andersen OK, Radanov BP, Villiger PM, ArendtNielsen L, Curatolo M (2004) Evidence for spinal cord hypersensivity in chronic pain after whiplash injury and in fibromyalgia. Pain 107:7-15

2. Barnsley L (2000) Epidemiology of whiplash. Ann Rheum Dis 59:394-396

3. Buitenhuis J, Spanjer J, Fidler V (2003) Recovery from acute whiplash: the role of coping styles. Spine 28:896-901

4. Curatolo M, Petersen-Felix S, ArendtNielsen L, Giani C, Zbinden AM, Radanov BP (2001) Central hypersensitivity in chronic pain after whiplash injury. Clin J Pain 17:306-315

5. Davidoff RA (1998) Trigger points and myofascial pain: toward understanding how they affect headaches. Cephalalgia 18:436-448

6. Freund BJ, Schwartz M (1999) Treatment of whiplash associated neck pain with botulinum toxin-A: report of 8 cases. J Rheumatol 26:756-758
7. Freund BJ, Schwartz M (2000) Treatment of chronic cervical-associated headache with botulinum toxin A: a pilot study. Headache 40:231-236

8. Freund BJ, Schwartz M (2000) Treatment of whiplash associated neck pain [corrected] with botulinum toxin-A: a pilot study. J Rheumatol 27:481-484

9. Frymoyer JW (1991) The Adult Spine: Principles and Practices: $1^{\text {st }}$ Edition. In: Raven Press, Ltd., New York, pp 172177

10. Gobel H, Heinze A, Heinze-Kuhn K, Jost WH (2001) Evidence-based medicine: botulinum toxin $\mathrm{A}$ in migraine and tension-type headache. J Neurol 248(Suppl 1):34-38

11. Hendriks EJ, Scholten-Peeters GG, van der Windt DA, Neeleman-van der Steen CW, Oostendorp RA, Verhagen AP (2005) Prognostic factors for poor recovery in acute whiplash patients. Pain 114:408-416

12. Juan FJ (2003) Treatment of neck pain after whiplash injuries with botulinum toxin-A injections. J Musculoskel Res $7(3 \& 4): 221-223$
13. Koelbaek JM, Graven-Nielsen T, Schou OA, Arendt-Nielsen L (1999) Generalised muscular hyperalgesia in chronic whiplash syndrome. Pain 83:229-234

14. Mork H, Ashina M, Bendtsen L, Olesen J, Jensen R (2004) Possible mechanisms of pain perception in patients with episodic tension-type headache. A new experimetal model of myofascial pain. Cephalalgia 24:466-475

15. Obelieniene D, Schrader H, Bovim G, Miseviciene I, Sand T (1999) Pain after whiplash: a prospective controlled inception cohort study. J Neurol Neurosurg Psychiatry 66:279-283

16. Ondo WG, Vuong KD, Derman HS (2004) Botulinum toxin A for chronic daily headache: a randomized, placebocontrolled, parallel design study. Cephalalgia 24:60-65

17. Padberg M, Bruijn de SFTM, Haan de RJ, Tavy DLJ (2004) Treatment of chronic tension-type headache with botulinum toxin: a double-blind, placebo-controlled clinical trial. Cephalalgia 24:675-680 
18. Partheni M, Constantoyannis C, Ferrari R, Nikiforidis G, Voulgaris S, Papadakis N (2000) A prospective cohort study of the outcome of acute whiplash injury in Greece. Clin Exp Rheumatol 18:67-70

19. Pobereskin LH (2005) Whiplash following rear end collisions: a prospective cohort study. J Neurol Neurosurg Psychiatry 76:1146-1151

20. Relja MA (2000) Treatment of chronic tension-type headache with botulinum toxin:1 year follow-up. Cephalalgia $20: 332$
21. Scholz J, Woolf CJ (2002) Can we conquer pain? Nat Neurosci 5(Suppl):1062-1067

22. Schrader H, Obelieniene D, Bovim G, Surkiene D, Mickeviciene D, Miseviciene I, Sand T (1996) Natural evolution of late whiplash syndrome outside the medicolegal context. Lancet 347:1207-1211

23. Schulte-Mattler WJ, Krack P (2004) Treatment of chronic tension-type headache with botulinum toxin A: a randomized, double-blind, placebocontrolled multicenter study. Pain 109:110-114
24. Spitzer WO, Skovron ML, Salmi LR, Cassidy JD, Duranceau J, Suissa S, Zeiss E (1995) Scientific monograph of the Quebec Task Force on Whiplash-Associated Disorders: redefining "whiplash" and its management. Spine 20(Suppl):1S-73S

25. Sterling M, Jull G, Vicenzino B, Kenardy J, Darnell R (2003) Development of motor system dysfunction following whiplash injury. Pain 103:65-73

26. Sycha T, Kranz G, Auff E, Schnider P (2004) Botulinum toxin in the treatment of rare head and neck pain syndromes: a systematic review of the literature. J Neurol 251:19-30 